\title{
ANALYSIS OF 2,4-D METABOLITES IN HIGHER PLANTS BY GAS CHROMATOGRAPHY
}

By

NORMAN CLINE GLAZE

\begin{abstract}
A DISSERTATION PRESENTED TO THE GRADUATE COUNCIL OF THE UNIVERSITY OF FLORIDA

IN PARTIAL FULFILLMENT OF THE REQUIREMENTS FOR THE DEGREE OF DOCTOR OF PHILOSOPHY
\end{abstract}

UNIVERSITY OF FLORIDA

April, 1966 


78.2
$6553 a$
AGRI.
GRTURAL
LIRARY

UNIVERSITY OF FLORIDA

31262085523339 


\section{ACKNOWLEDGEMENTS}

The author wishes to express his sincere appreciation to Dr. M. Wilcox, Dr. S. H. West, Dr. T. E. Humphreys, and Dr. H. C. Harris for their advice and guidance during the course of these studies.

Special acknowledgement is made to Professor Zygmunt Eckstein, Katedra Technologii Organicznej II Politechniki, Warsaw, for supplying reprints and translations of necessary passages from his works, to Dr. G. R. Powell, Unit of Experimental Agronomy, University of Oxford, who supplied samples and physical properties of 4-hydroxy-2,3-dichloro- and 4-hydroxy-2,5-dichlorophenoxyacetic acids and to Dr. R. H. Biggs for use of his gas chromatograph.

This work was made possible by a grant from the American Cancer Society. 
ACKNOWLEDGEMENTS. . . . . . . . . . . . . .

LIST OF TABLES. . . . . . . . . . . . . . .

INTRODUCTION. .....................

LITERATURE REVIEW . . . . . . . . . . . . . 3

MATERIALS AND METHODS ............... 17

EXPERIMENTAL RESULTS. . . . . . . . . . . . 28

DISCUSSION. . . . . . . . . . . . . 34

SUMMARY ............................... 40

IITERATURE CITED. . . . . . . . . . . . . 42 


\section{LIST OF TABLES}

Table

Page

1 Operating Conditions for Gas Chromatography. . . 29

2 Retention Times of Standard Solutions in Methanol............. 30

3 Relative Peak Heights of Methyl and Propyl Esters

of the Propyl Ethers........... 32 


\section{INTRODUCTION}

The use of herbicides is increasing rapidiy year by year. 2,4-Dichlorophenoxyacetic acid $(2,4-D)$ is the most widely used of the herbicides offered on the market. Although 2,4-D was one of the first selective herbicides discovered and has been investigated by many workers over the years, there are still many questions concerning its metabolism.

Hydroxylated derivatives have been found in some microorganisms and plants. This might be expected as hydroxylation is a prime method of detoxication in biological systems. 2,4-D has been found to be hydroxylated predominantly in the 5-position. However, 4hydroxy-2,3- and 4-hydroxy-2,5-dichlorophenoxyacetic acids have been Identified in some cases. This is interesting as it involves much more elaborate mechanisms than hydroxylation in a vacant position. The formation of these hydroxy acids requires a chlorine shift to one of the meta positions and hydroxylation in the para position. The object of this work is to determine whether hydroxylated derivatives are formed by excised roots from 2,4-D or related herbicides. Some workers have also found muconic acids and gamma-lactones as succeoding stages in the metabolism of these herbicides. This would follow from an oxidative degradation of the ring structure. The lactones found are of interest from the public health standpoint. The gamma-lactones isolated contain double bonds in the 
even numbered positions and compounds of this type have been found to be carcinogenic. If these compounds appear in any appreciable amounts and are not very transitory in nature, the use of the herbicides involved might require reevaluation by regulating organizations. 


\section{LITERATURE REVIEW}

The literature review will be restricted to the metabolism of chloro- and methylphenoxyaliphatic and naphthyl- and naphthyloxyaliphatic acids by higher plants and microorganísms. Animal metabolism is covered by Williams $(1950,1959)$. He states that phenoxyacetic acid and the ortho- and para-chloro-derivatives are unchanged in animals. General classes of compounds which are considered to be metabolites, such as phenols, catechols, etc., are discussed in his publications.

Newman and Thomas (1949) discovered that the persistence of 2,4-dichlorophenoxyacetic acid $(2,4-D)$ in soils was decreased by pretreatment of the soil with 2,4-D and certain other compounds having similar substituent groups such as 2,4-dichlorophenol. However, pretreatment with some compounds such as 2- or 3-chlorophenol or phenoxyacetic acid had no effect on the persistence of 2,4-D in the soil. Burger et al. (1962) measured the persistence of some phenoxyaliphatic acids by a bioassay technique using alfalfa seedlings. Acetic, alpha-propionic, alpha-butyric and gamma-butyric acid homologs were toxic when applied to soil planted to alfalfa, but beta-propionic acid analogs were not toxic to the test species. Prolonged persistence was exhibited when the soil was treated with 3,4-dichloro- and 2,4,5-trichlorophenoxyaliphatic acids. The duration of phytotoxícity in soil receiving 4-chloro-, 2,4-dichloro- and 
2-methyl-4-chlorophenoxyaliphatic acids was governed by the type and linkage of the aliphatic side chain. Audus (1952) found that 2,4-D enriched soil metabolized 2-methyl-4-chlorophenoxyacetic acid (MCPA) immediately but did not affect the detoxication of 2,4,5-trichlorophenoxyacetic acid $(2,4,5-T)$. MCPA enriched soil degraded 2,4-D and $2,4,5-T$.

Audus (1950) isolated Bacterium globiforme which was capable of detoxifying 2,4-D. A Flavobacterium sp. was found by Burger et al. (1962) which degraded phenoxybutyric acids. Only phenoxybutyric acids having no meta-chlorine on the aromatic ring were metabolized by the organism. These results show that the persistence of these herbicides in soils is governed by the specific structural characteristics of the molecule. A Corynebacterium sp., capable of degrading 2,4-D and MCPA, was isolated by Rogoff and Reid (1956). From all indications, the ring was ruptured and complete destruction of the molecule followed.

Audus (1952) suggested that the first step in the degradation of 2,4-D, 2,4,5-T and MCPA might be the removal of the two carbon side chain leaving a phenol. However, he found no accumulation of phenols in soil treated with any of these herbicides. If a phenol is an intermediate, it must be metabolized as rapidly as it is formed. This is a possibility because it was found that 2,4dichlorophenol decomposed rapidly when added to a 2,4-D enriched soil.

Leafe (1962) suggested two possibilities for the metabolism of MCPA by Galium aparine. The first postulate listed for the 
degradation of MCPA was the removal of the two carbon side chain either as a two carbon fragment or its loss as carbon dioxide. Secondly, he suggested that the metabolism or detoxication might involve conjugation to another cellular component. Leafe stated that the detoxication of the molecule by loss of both carbon atoms of the side chain has been established as the reason Galium aparine is resistant to $\mathrm{MCPA}$.

Measurements were made by Canny and Markus (1960) of the rate of evolution of labelled carbon dioxide from the shoots and roots of Vicia faba which had been treated on one leaflet with 2,4-D labelled in the carboxyl group. The carbon dioxide evolved from the roots was more radioactive than that from the shoot. Labelled carbon was shown to be ircorporated into many compounds in the root. This is evidence that the degradation may take place mainly in the roots. It was also concluded that although metabolism of the alkyl side chain was rapid, this was not the main pathway for inactivation of the herbicide.

Bach (1961), working with stems of Phaseolus vulgaris, isolated one half of the original radioactivity from carboxyl labelled 2,4-D in an ether extract. The activity was found to be distributed among ten components. Tests for functional groups showed that these components retained the aromatic character of 2,4-D. Neither 2,4-D nor 6-hydroxy-2,4-dichlorophenoxyacetic acid were isolated. Some ten amino acids wore also labeliled in the treated stem tissue. When red kidney beans were treated with labelled 2,4-D, Holley (1952) found that in one week two thirds of the radioactivity was 
recovered in a water soluble fraction. He stated that the water soluble material must be a derivative of an unknown acid rather than of 2,4-D. Holley suggested that the unknown acid might be 3-, 5or 6-hydroxy-2,4-dichlorophenoxyacetic acid.

Steenson and Walker (1956) isolated Flavobacterium peregrinum and two Achromobacter sp. Which were capable of decomposing 2,4-D, MCPA or 4-chlorophenoxyacetic acid. They found that pretreatment of the soil with one of the compounds accelerated the rate of decomposition of the other two. In a liquid medium, F. peregrinum metabolized 2,4-D and liberated 76 per cent of the chlorine in ionic form. They suggested that 4-chloro-2-hydroxyphenoxyacetic acid and 4-chlorocatechol might be intermediates in the degradation of 4chlorophenoxyacetic acid.

A small, Gram-negative, motile organism was isolated from the soil by Evans and Smith (1954) which utilized 4-chlorophenoxyacetic acid and 2,4-D and produced 4-chlorophenol and 2,4-dichlorophenol, respectively. A phenolic acid metabolite was found and it was suggested to be 6-hydroxy-2,4-dichlorophenoxyacetic acid. It was also observed that the chlorine atoms were retained until the aromatic character of the molecule was destroyed.

Using a replacement culture technique, Byrde and Woodcock (1957) showed that phenoxyacetic and beta-phenoxypropionic acids were hydroxylated mainly in the para position by Aspergillus niger. The compounds were also hydroxylated in the ortho position but to a lesser extent. Gamma-phenoxy-n-butyric acid also was metabolized 
mainly to 4-hydroxyphenoxyacetic acid by hydroxylation and betaoxidation. Delta-phenoxy-n-valeric acid was degraded in a similar manner to beta-(4-hydroxyphenoxy)propionic acid.

Wilcox et al. (1963) found that barley, oats and corn had the ability to produce a ring hydroxylated intermediate from a phenoxyn-aliphatic acid with an even number of carbons in the side chain when incubated in aerated water. Odd chain homologs yielded little of a hydroxylated metabolite. In soybeans, alfalfa and peanuts, no hydroxylated intermediates were detected. The phenolic product, produced by the test plants when treated with various phenoxy-naliphatic acids having an even number of carbons in the side chain, was identical with 4-hydroxyphenoxyacetic acid. These data suggest that ring hydroxylation by the resistant grass species coincides with the suggested role of hydroxylation as a detoxication mechanísm.

Working with Aspergillus niger, Byrde and Woodcock (1957) demonstrated that phenoxyacetic and beta-phenoxypropionic acids were hydroxylated in the para position mainly and to a lesser extent in the ortho position. Faulkner and Woodcock (196la, 1961b) alsc found phenoxyacetic acid to be hydroxylated in the ortho and para positions. Clifford and Woodcock (1964), however, found 2-hydroxyphenoxyacetic acid to be the main metabolite from phenoxyacetic acid. Bocks et al. (1964) also found 2-hydroxyphenoxyacetic acid to be the main metabolite from phenoxyacetic acid. All other isomers were formed but in much smaller amounts. Bocks also found phenol to be a minor product. Faulkner and Woodcock (1961b) found that 2-chloro- 
and 4-chlorophenoxyacetic acids were metabolized to 2-chloro-4hydroxy- and 4-chloro-2-hydroxyphenoxyacetic acids, respectively. The original starting materials were monohydroxylated in all vacant positions but the above were produced in much larger amounts. Also found was 2-hydroxyphenoxyacetic acid." This was the first example of fungal replacement of chlorine by a hydroxyl group. Bocks et al. used methoxybenzene as a substrate and observed that 2 -hydroxymethoxybenzene was produced. If the incubation was stopped after three days, phenol was present in almost the same proportions as 2-hydroxymethoxybenzene. If allowed to proceed for a longer period, the yield of phenol relative to 2 -hydroxymethoxybenzene decreased.

Evans and Moss (1957), working with a Pseudomonas sp., extracted 2-hydroxy-4-chlorophenoxyacetic acid and 4-chlorocatechol from cultures grown on a medium containing 4-chlorophenoxyacetic acid. This was a strong indication that these were two of the possible intermediates in the degradation of this herbicide.

Bell (1960), studying an Achromobacter sp., found an adaptive system that is capable of oxidizing 2,4-D. The organism can also oxidize many 2,4-D analogs. For the oxidation rate to be comparable to 2,4-D, the organism appeared to require the following: a free ortho position; a free carboxyl group on the side chain, preferably beta to the ethereal linkage; a chlorine atom in the para position; and no more than two chlorine atoms on the ring whether or not an ortho position is free. He suggested that the probable degradation route was to 2,4-dichlorophenol but that action by a decarboxylase to 2,4-dichloromethoxybenzene might be involved. He 
also suggested that the metabolites from 2,4-dichlorophenol might be 4-chlorocatechol or 3,5-dichlorocatechol.

The metabolism of 2,4-D and MCPA by a strain of Flavobacterium peregrinum and an Achromobacter sp. Was studied by Steenson and Walker (1957). The evidence presented indicated that adapted organisms metabolize 2,4-D through 2,4-dichlorophenol and 4-chlorocatechol and that MCPA is degraded to 4-chloro-2-methylphenol. Bacteria, grown on a medium containing 2,4-D, did not oxidize any of the five possible isomers but would oxidize 2,4-dibromo-, 4-bromo2-chloro-, 4-chloro- and to a small extent, 2-chlorophenoxyacetic acids.

Thomas $\theta$ al. $(1963,1964 a)$ studied the hydroxylation of some phenoxyacetic acids by stem tissue of Avena sativa. They found that phenoxyacetic acid was converted to 4-hydroxyphenoxyacetic acid. Phenoxyacetic acids with an unsubstituted para position were hydroxylated in that position. The phenolic acids were accumulated as the 4-O-beta-D-glucosides. Phenoxyacetic acids with a chlorine atom in the para position, however, were not hydroxylated to an appreciable extent. These acids accumulated as neutral products which proved to be phenoxyacetylglucoses. In the case of 2,4,6-trichIorophenoxyacetic acid, however, hydroxylation took place at the meta position and the glucoside was isolated.

Thomas et aI. (1964b) studied the metabolism of 2,4-D in stem tissue of Phaseolus vulgaris. They found the predominant metabolite to be 4-hydroxy-2,5-dichlorophenoxyacetic acid. This shows that the hydroxylation and chlorine shift discovered first in Aspergillus 
niger also occurs in higher plants. A minor metabolite was show to be 4-hydroxy-2,3-dichlorophenoxyacetic acid which also requires the hydroxylation and chlorine shift. The products accumulated within the tissue as beta-gIucosides.

Evans and Moss (1957), using a Gram-negative, motile organism of the Pseudomonas type, found that when it was incubated with $4-$ chlorocatechol, beta-chloromuconic acid accumulated. The betachloromuconic acid was further metabolized and the chlorine liberated in ionic form. Later Fernley and Evans (1959) isolated alpha-chloromuconic acid during the metabolism of 2,4-D which was identical with that prepared by the oxidation of 2-chlorophenol. They observed the shift of the $283 \mathrm{mu}$. peak of 2,4-D in the ultraviolet range to another peak at $272 \mathrm{m \mu}$.

Schemes for the metabolism of chlorophenoxyacetic acids by soil bacteria were reported by Rogoff (1961), in which 4-chlorophenoxyacetic acid was metabolized through 2-hydroxy-4-chlorophenoxyacetic acid and 4-chlorocatechol to beta-chloromuconic acid and 2,4-D was degraded through 2,4-dichlorophenol and 3,5-dichlorocatechol to alpha-chloromuconic acid. Evans and Smith (1951), Evans et al. (1951), Dagley et al. (1960), Ribbons and Evans (1962) and Rogoff all show schemes for further microbial oxidation of catechol type derivatives. In all cases, the schemes show the catechol to ciscis-miconic acid step and terminate with beta-ketoadipic acid. The steps between the cis-cis-muconic acid and beta-ketoadipic acid appear to be somewhat uncertain. The uncertainty seems to be whether the intermediates are lactonized or not when the double 
bond migrates, which must occur if this scheme is to be correct. The beta-ketoadipic acid is presumed to be split into acetic and succinic acids which would pass into the tricarboxylic acid cycle. Working with a Gram-negative soil bacterium, Gaunt and Evans (1961) found that the ultraviolet peaks of MCPA at 228 and 279 mu. are replaced by a peak at $277 \mathrm{m \mu}$. The properties of this compound were consistent with the lactonic acid, alpha-methyl-gamma-carboxymethylene- $\Delta^{\alpha}$-butenolide. Peracetic acid oxidation of 4-chloro-2methylphenol produced a compound with the same properties. A phenolic acid was also isolated and found to have properties consistent with a hydroxy-2-methyl-4-chlorophenoxyacetic acid. It was believed to be the 6-hydroxy-derivative. 4-ChIoro-2-methylphenol was also isolated from the extracts. The following metabolic pathway for the degradation of MCPA was suggested: MCPA through 6hydroxy-4-chloro-2-methylphenoxyacetic acid; 5-chloro-3-methylcatechol; alpha-methyl-gamma-chloromuconic acid; alpha-methyl-gammacarboxymethylene- $\Delta^{\alpha}$-butenolide; alpha-methylmaleylacetate and to smaller fragments prior to entering a terminal respiratory cycle.

The lactones mentioned in the degradation schemes are of considerable interest because butenolides of this general type with double bonds in even numbered positions have been shown to be carcinogenic by Dickens and Jones (1961, 1963).

Byrde et al. (1956), using a replacement culture tochnique of Aspergillus niger, found that omega-(2-naphthyloxy)-n-aliphatic acids having an even number of carbons in the side chain were beta-oxidized to (6-hydroxy-2-naphthyloxy)acetic acid. Beta-(2-naphthyloxy)propionic 
acid was transformed to beta-(6-hydroxy-2-naphthyloxy)propionic acid. The n-butyric homolog was hydroxylated in the six position before beta-oxidation to (6-hydroxy-2-naphthyloxy)acetic acid. Hydroxylation of the acetic and propionic acids led to a decrease in toxicity to the fungus. Byrde and Woodcock (1958), working with Sclerotinia laxa, found that nuclear hydroxylation was virtually absent with this organism. They did find that gamma-(2-naphthyloxy)-n-butyric and delta-(2-naphthyloxy)-n-valeric acids underwent beta-oxidation to the corresponding acetic and propionic acids, respectively. They also found beta-naphthol was produced from beta-(2-naphthyloxy)propionic acid.

Fawcett et al. (1954) found that omega-phenoxy-n-aliphatic acids with an odd number of carbons in the side chain yielded a substantial amount of phenol when applied to flax plants. Compounds with an eyen number of carbon atoms in the side chain were beta-oxidized to the acetic derivative. The decanoic homolog, however, was found to produce a large amount of phenol. This was best explained from the fact that omega-oxidation has been shown in animals for some compounds with fatty acids of nine or ten carbon atoms. It was assumed that this was also occurring in the flax plant.

Omega-(4-chlorophenoxy)aliphatic and omega-(2,4-dichlorophenoxy)aliphatic acids showed the characteristic alternation of activity in work by Wain and Wightman (1954), when used in the Went pea test, the tomato leaf epinasty and the wheat cylinder test. Only the wheat cylinder test showed activity with even numbered aliphatic acids of the 2,4,5-trichlorophenoxy series. When solutions of the 
2,4,5-trichlorophenoxyaliphatic acids with side chains containing an even number of carbon atoms were pretreated with wheat cylinders, however, the alternation of activity was shown by the Went pea test and the tomato leaf epinasty test. This evidence showed that wheat possessed the ability to beta-oxidize this series but that pea and tomato did not. When omega-l-naphthylaliphatic acids were tested, the Went pea test and wheat cylinder test showed the alternation of activity but only the acetic homolog was active in the tomato leaf epinasty test. It was found that the substitution of alkyl groups in the alpha position did not hinder beta-oxidation, but substitution in the beta position did prevent beta-oxidation.

Webley et aI. (1955) studied the breakdown of omega-phenylaliphatic acids by Nocardia opaca. They found that acids with an odd number of carbon atoms in the side chain were converted to benzoic acid and that cinnamic acid was an intermediate. Orthohydroxyphenylacetic acid was found to be a metabolite when acids with an even number of carbon atoms in the side chain were used in the growth medium. Benzoic acid was produced essentially quantitatively but ortho-hydroxyphenylacetic acid was not, indicating that it must arise from some side reaction. They stated that the latter accumulates because it is not metabolized further by this organism. The evidence suggested that $\underline{N}$. opaca was capable of beta-oxidation of the fatty acid side chains of these phenylaliphatic acids.

Webley et al. (1958) expanded their study to examine the effect of change of various groups in the molecule and how beta-oxidation would be affected. They found the following five factors to affect 
beta-oxidation: 1) an oxygen bridge between the fatty acid and the ring; 2) ring substitution, particularly in the ortho position; 3) the nature of the ring substituents; 4) the type of ring structure to which the fatty acid is attached; and 5) the position of attachment of the fatty acid. The side chain of phenylbutyric acid was beta-oxidized more readily than phenoxybutyric acid. The position of substituted chlorine atoms in the ring affected beta-oxidation as follows: gamma-(3-chlorophenoxy)butyric acid was degraded most rapidly; the 4-chloro-homolog was intermediate; and the 2-chlorocompound was the least reactive. Monomethyl homologs reacted in the same manner as the corresponding monochloro-compounds. The methyl homologs, in general, were beta-oxidized more readily than the corresponding chloro-compounds. The rate of conversion of the betahydroxy-intermediate is reduced with the chlorinated materials. 2-Methyl-4-chIoro- and 2,4-dichlorophenoxybutyric acids were tested to evaluate the effect of disubstitution. It was found that disubstitution decreased the rate of beta-oxidation. The oxidation of the disubstituted compounds proceeded to the beta-hydroxy-derivative but the acetic homologs were not produced. The caproic homologs were rapidly converted to the butyrics but again none of the acetic homologs were obtained. Gamma-(2-naphthyloxy)butyric and beta-(2naphthyloxy)propionic acids were beta-oxidized to the corresponding acetate and 2-naphthol, respectively. The l-naphthyloxy-derivatives remained unchanged throughout the experiment. Gamma-(I-naphthyI)butyric acid was converted to the acetate while the corresponding naphthyloxy-compound was unchanged. Beta-oxidation of the fatty 
acid side chain was most rapid when attached to a phenyI ring and slowest when attached to a I-naphthyl group. The indolyl group was intermediate.

Fawcett et al. (1959), using the wheat cylinder, pea curvature, pea cogment and tomato leaf epinasty tests, assayed the growthregulating activities of 18 homologous series of omega-phenoxyaliphatic acids with two to seven carbon atoms in the side chain and with chlorine and methyl groups substituted in various ring positions. The degradation of some homologs was investigated and identification of metabolites made by chromogenic methods and bioassay. They noted that there were four patterns of biological activity as follows: I) where beta-oxidation was operative, and the acetic acid was active while the propionic acid was not, only the even numbered homologs showed activity; 2) where beta-oxidation was hindered at the butyric stage, and the acetic acid was active but the propionic acid inactive, only the acetic acid showed activity; 3) where beta-oxidation was operative, and both the acetic acid and propionic acid were active, all members showed activity; and 4) where beta-oxidation was hindered at the butyric stage, and the acetic acid was less active than the propionic acid, the acetic acid plus all odd numbered homologs showed activity. The results indicated that beta-oxidation is hindered at the butyric stage in pea and tomato tissue. The hindrance at the butyric stage was shown to be associated with an ortho chlorine or methyl group on the ring. This effect was largely removed by a further chlorine atom in the para position. Addition of a chlorine atom in tho meta position 
had no effect. The beta-oxidation sequence was not changed when a methyl group was substituted for a chlorine atom. 


\section{MATERIALS AND METHODS}

The excised roots were prepared in the following manner: a single layer of seed was placed between double thicknesses of cheesecloth supported on aluminum mesh over a dishpan of aerated water. These were germinated in a growth chamber in the dark at $7 I^{\circ} \mathrm{F}$ for a period of 4 to 7 days depending on the species. At the end of this period, except in the case of alfalfa, the roots protruding below the aluminum mesh were excised with a razor blade and used in subsequent incubations. The alfalfa roots did not grow through the cheesecloth and, therefore, the top layer of cheesecloth was removed and the seed cut off with scissors, after which the roots were used in the incubation studies. The species used were as follows: Coker 67 field corn (Zea mays L.), Hadden wheat (Triticum aestivum L.), Moregrain oats (Avena sativa L.), Manchuria $X$ Rabat barley (Hordeum vulgare I.) and Hairy Peruvian alfalfa (Medicago sativa I.).

Erlenmeyer flasks ( $300 \mathrm{ml}$.) were used as incubation vessels. Tetracycline and streptomycin at concentrations of 2 and $30 \mathrm{ppm}$, respectively, were used to prevent buildup of microbial populations. Sets were run using $0.4 \mathrm{M}$ tris [2-amino-2-(hydroxymethyl)-1,3propanediol] buffer ( $\mathrm{pH} \mathrm{7.4)} \mathrm{and} 0.4 \mathrm{M}$ phosphate buffer ( $\mathrm{pH}$ 5.2) at a final concentration of $2 \times 10^{-2} \mathrm{M}$. The treatment flasks were made $1 \times 10^{-3} \mathrm{M}$ in the potassium salt of 2,4-D. All flasks were brought 
to a final volume of $100 \mathrm{ml}$. Roots ( $10 \mathrm{~g}$. fresh weight) were then added to the flasks. The flasks were covered with a tissue and put on a shaker at approximately 60 cycles per minute. A total of 12 flasks were used for each species. Six blank flasks were used as wөIl as six containing 2,4-D.

The incubations using tris buffer were incubated for 10 hours. At the end of this time, the roots were removed from the flasks and frozen in cold methanol. The roots were then ground in an omimixer, keeping them frozen by immersing the vessel in a bath at $-50^{\circ} \mathrm{C}$ or colder. After grinding, the solution was centrifuged at $17,500 \mathrm{rpm}(37,000 \mathrm{Xg})$ for 30 minutes. The supernatant fraction was concentrated to approximately $10 \mathrm{ml}$. by fre日ze drying. Each blank and treatment was split in half. To one portion of each, 40 per cent sodium hydroxide was added so that the final solution was 10 per cent in sodium hydroxide. This solution was refluxed for 20 minutes in order to hydrolyze any esters present. The hydrolyzed sample was brought to $\mathrm{pH} 3$ with sulfuric acid and freeze dried. Methanol was added to dissolve any hydroxylated derivatives that might be present. The hydrolyzed and unhydrolyzed samples were then reduced under a stream of nitrogen to a volume of approximately $1 \mathrm{mI}$. and applied to $8 \times 8$ inch plates spread to a thickness of $1 \mathrm{~mm}$. with silica gel G (E. Merck Ag., Darmstadt) for thin layer chromatography. These plates were run in chambers with an ether:ligroin (b.p. $\left.66-75^{\circ} \mathrm{C}\right)$ :formic acid $(50: 50: 2)$ solvent system. After drying, the silica gel $G$ between the origin and the solvent front was scraped from the plate. This carrier was then eluted with acetone. 
The acetone extracts were reduced under a stream of nitrogen to approximately $10 \mathrm{ml}$. and split again. One portion was set aside. The others were reduced under a stream of nitrogen to approximately $.5 \mathrm{ml}$. after which the volume was adjusted to $1 \mathrm{ml}$. with methanol. These samples were treated with an ethereal solution of diazo-npropane. More of the diazo-n-propane solution was added as necessary to keep the color of the solutions yellow. After 30 minutes, two drops of a solution of boron trifluoride ( 0.7 per cent) in methanol were added to further catalyze the reaction and the solutions were kept yellow for an additional 30 minutes. At the end of this time, the samples were again concentrated under nitrogen and adjusted to a volume of $1 \mathrm{ml}$. These solutions were used for analysis by gas chromatography.

The incubation mixtures containing phosphate buffer were treated similarly except that the extraction of the roots was carried out by dropping the roots into boiling methanol and boiling an additional 20 minutes. Both halves of the split samples were also used in this case as two diazo compounds were used. One portion was treated with diazomethane while the other was treated with diazo-n-propane as in the previous case. Otherwise, both sets were handled as described previously.

Solutions of 2,4-, 6-hydroxy-2,4-, 5-hydroxy-2,4-, 4-hydroxy2,3- and 4-hydroxy-2,5-dichlorophenoxyacetic acids in methanol were prepared and treated with diazomethane and diazo-n-propane as described previously. The final concentration of these solutions was $2.5 \mathrm{mg} \cdot / \mathrm{ml}$. These solutions were used as standards for gas chromatography. 
Mixtures of some synthesized compounds ( $10 \mathrm{mg} \cdot$ ) and lanolin (4 g.) were prepared for tomato epinasty tests. The following compounds were tested: 5-nitro- and 5-amino-4-chloro-2-methylphenoxyacetic acids; ethyl 3-amino-2,4-dichlorophenoxyacetate; 4-hydroxy2,3-, 4-hydroxy-2,5-, 6-hydroxy-2,4- and 5-hydroxy-2,4-dichlorophenoxyacetic acids. 2,4-D was also included as a standard. Approximately $300 \mathrm{mg}$. of the lanolin mixtures of these compounds were spotted on the petiole of the youngest fully developed leaf of two month old tomato plants in the greenhouse. Daily observations were made to observe the effects of the compounds on the plants.

All melting points were run on a Kofler micro hot stage apparatus and the temperatures corrected. The compounds were synthesized as follows :

Diazomethane. - Potassium hydroxide $(40 \mathrm{ml}$. of 30 per cent solution) and anhydrous ethyl ether ( $160 \mathrm{ml}$.) were placed in a large test tube and immersed in an insulated container holding an antifreeze solution at $-10^{\circ} \mathrm{C}$ or lower. The contents of the tube were allowed to cool for 20 minutes. N-methyl-N-nitro-N-nitrosoguanidine $(8 \mathrm{~g}$.$) was added to the tube. The bath temperature was allowed to$ rise only to $0^{\circ} \mathrm{C}$. The reaction is complete when the ether assumes a yellow color and the solid matter disappears and usually is complete in about 30 minutes. The ethereal solution was poured off into a polyethylene bottle containing potassium hydroxide pellets. The solution should be stored in a freezer and used within 24 hours for best results. 
Diazo-n-propane. - Potassium hydroxide $(20 \mathrm{ml}$. of 60 per cent solution) and anhydrous ethyl ether ( $160 \mathrm{ml}$.) were placed in a large test tube and cooled as described abuve. N-propyl-N-nitrosourea ( $8 \mathrm{g.})$, prepared previously by M. Wilcox, was added to the tube. The reaction is complete when the ether assumes a deep yellow color and the solid matter suspended in the potassium hydroxide loses its yellow color, becoming white. The ethereal solution was poured off as in the case of diazomethane. This solution should be stored in a freezer and used within 24 hours for best results.

Monoperphthalic acid. - An ethereal solution of monoperphthalic acid was prepared as described by Payne (1962). The solution was standardized by adding $30 \mathrm{ml}$. of 20 per cent potassium iodide solution to $2 \mathrm{ml}$. of the ethereal solution and, after 10 minutes, titrating the liberated iodine with $0.06268 \mathrm{~N}$ sodium thiosulfate. This solution was used in subsequent attempted preparations.

Isopropyl 4-chloro-2-methylphenoxyacetate. - To 95 per cent 4-chloro-2-methylphenoxyacetic acid (2l2 g•) was added 2-propanol $(264 \mathrm{~g} \cdot)$. Boron fluoride ethyl ether $(178 \mathrm{~g} \cdot)$ was added dropwise and the mixture refluxed for 4 hours. The excess alcohol was distilled off and the solution neutralized with a 10 per cent solution of sodium carbonate. The solution was then extracted with three portions of ethyl ether and the ether removed under vacuum. The remaining liquid was vacuum distilled ( $15 \mathrm{~mm} . \mathrm{Hg}$ ) and the portions distilling over between 170 and $174^{\circ} \mathrm{C}$ collected and combined. The weight of these portions was $193.6 \mathrm{~g}$. (79.8 per cent yield). 
5-Nitro-4-chloro-2-methylphenoxyacetic acid. - This compound was prepared as described by Eckstein et al. (1964). The compound melted at $151-152^{\circ} \mathrm{C}$. Faulkner and Woodcock (1965) reported 152 $153^{\circ} \mathrm{C}$.

5-Amino-4-chloro-2-methylphenoxyacetic acid. - This compound was also prepared as described by Eckstein et al. (1964). The compound melted at $194-197^{\circ} \mathrm{C}$. Eckstein et al. (1964) reported $197-198^{\circ} \mathrm{C}$. The ethyl ester, prepared by the previously described boron trifluoride method, melted at $76-78^{\circ} \mathrm{C}$ (Found: C, 54.51; H, 5.96; N, 5.95; Cl, 14.38. $\mathrm{C}_{11} \mathrm{H}_{12} \mathrm{NO}_{3}$ requires $\mathrm{C}, 54.22 ; \mathrm{H}, 5.79 ; \mathrm{N}, 5.75$; CI, 14.55 per cent). Faulkner and Woodcock (1965) reported 79$80^{\circ} \mathrm{C}$.

6-Nitro-4-chloro-2-methylphenol. - This compound was prepared as described by Zincke (1918). He reported the melting point to be $107^{\circ} \mathrm{C}$. Our preparation melted at $106^{\circ} \mathrm{C}$ (Found: C, 44.96; H, 3.47; $\mathrm{Cl}, 18.32 ; \mathrm{N}, 7.42 . \mathrm{C}_{7} \mathrm{H}_{6} \mathrm{ClNO}_{3}$ requires $\mathrm{C}, 44.82 ; \mathrm{H}, 3.22 ; \mathrm{Cl}, 18.90$; N, 7.47 per cent).

Ethyl 6-nitro-4-chloro-2-methylphenoxyacetate. - 6-Nitro-4chloro-2-methylphenol ( $30 \mathrm{~g}$.$) was added to a solution of sodium ( 3.7$ g.) In $300 \mathrm{ml}$ of absolute ethanol and heated to reflux. Ethyl bromoacetate $(20 \mathrm{~g}$.$) was added dropwise through the condenser and the$ mixture refluxed for 3.5 hours. Most of the ethanol was removed under vacuum. The mixture was then diluted with water and the precipitate filtered off. The yield was $32 \mathrm{~g} \cdot$ (75 per cent yield). The compound melted at $70^{\circ} \mathrm{C}$. Faulkner and Woodcock (1965) also reported a melting point of $70^{\circ} \mathrm{C}$. 
6-Nitro-4-chloro-2-methylphenoxyacetamide. - Ethyl 6-nitro-4chloro-2-methylphenoxyacetate ( $5 \mathrm{~g}$.) was added to $20 \mathrm{ml}$. of absolute ethanol and refluxed with $5 \mathrm{ml}$. of concentrated ammonium hydroxide. The mixture was allowed to reflux for 8 hours and $5 \mathrm{ml}$. of concentrated ammonium hydroxide was added at 2 hour intervals. The yield of product was $1.2 \mathrm{~g}$. (27 per cent yield). The compound melted at $153-156^{\circ} \mathrm{C}$.

5-Chloro-3-methylcatechol. - Attempts were made to prepare this compound through two intermediates described by Zincke (1918). The structures given for the intermediates were dubious. In one trial, however, a small amount of the desired product was obtained which agreed with the melting point of $89^{\circ} \mathrm{C}$ (Found: C, 53.31; H, 4.54; $\mathrm{Cl}, 22.05 . \mathrm{C}_{7} \mathrm{H}_{7} \mathrm{ClO}_{2}$ requires $\mathrm{C}, 53.02 ; \mathrm{H}, 4.45 ; \mathrm{Cl}, 22.36$ per cent) reported by Zincke. The last step in the synthesis was very low yielding, the product unstable and results inconsistent. Since the preparation of 2-methyl-1,4-muconolactone from this compound failed, further attempts to prepare it were terminated.

4-Chloro-2-methylmuconic acid. - 4-Chloro-2-methylphenol (4.0 g.) was added to $175 \mathrm{ml}$. of ether containing monoperphthalic acid (17 g.) and allowed to stand at room temperature for four days. None of the desired product was obtained when the preparation was treated as described by Testa (1952).

2-Methyl-1,4-muconolactone. - 3-Methyl-5-chlorocatechol（1.08 g.) was dissolved in $50 \mathrm{ml}$. of ether and $88 \mathrm{ml}$. of ether containing monoperphthalic acid $(4.34 \mathrm{~g}$ ) added. This mixture was allowed to 
stand at room temperature for five days. None of the desired product was obtained when the preparation was treated as described by Testa (1952).

6-Hydroxy-2,4-dichlorophenoxyacetic acid (6-OH-2,4-D). - This compound was prepared as described by Cavill and Ford (1954) using 3,5-dichlorocatechol previously prepared in this laboratory. The compound after two recrystallizations from water melted at $133^{\circ} \mathrm{C}$. Cavill and Ford reported the melting point to be $132^{\circ} \mathrm{C}$.

2-Chloro-1,4-muconolactone. - 2-Chlorophenol (6.0 g.) was added to $164 \mathrm{ml}$. of ether containing monoperphthalic acid $(9.1 \mathrm{~g} \cdot)$. On the following day, $90 \mathrm{ml}$. of ether containing monoperphthalic acid $(5.0 \mathrm{~g}$.$) was added and the solution allowed to stand for four days$ at room temperature. This preparation, when worked up, failed to yield the desired product.

5-Hydroxy-2,4-dichlorophenoxyacetic acid hydrate (5-OH-2,4-D). This compound was prepared as described by Moszew and Wojciechowski (1945). The product after two recrystallizations from water melted at $166^{\circ} \mathrm{C}$ (Found: $\mathrm{C}, 37.62 ; \mathrm{H}, 3.03 ; \mathrm{Cl}, 27.42 . \mathrm{C}_{8} \mathrm{H}_{6} \mathrm{Cl}_{2} \mathrm{O} \cdot \mathrm{H}_{2} \mathrm{O}$ requires C, 37.67; H, 3.16; CI, 27.80 per cent). Moszew and Wojciechowsk1 (1945) reported the melting point to be $175.5^{\circ} \mathrm{C}$.

3-N1tro-2,4-dichlorophenol. - This compound was prepared as described by Groves et al. (1929). After two recrystallizations from 2,2,4-trimethylpentane, the compould melted at $72^{\circ} \mathrm{C}$. Groves et al. found their preparation to melt at $70-72^{\circ} \mathrm{C}$.

Ethyl 3-nitro-2,4-dichlorophenoxyacetate. - This compound was prepared as described by Faulkner and Woodcock (1965). It was 
found to melt from $80-82^{\circ} \mathrm{C}$. Faulkner and Woodcock reported the melting point to be $85^{\circ} \mathrm{C}$.

Ethyl 3-amino-2,4-dichlorophenoxyacetate. - Ethyl 3-nitro-2,4dichlorophenoxyacetate $(36 \mathrm{~g}),$.10 per cent palladium on charcoal ( $2 \mathrm{g.}$ ) and $150 \mathrm{ml}$. of tetrahydrofuran were added to a bomb with a total volume of $430 \mathrm{ml}$. The bomb was charged with nitrogen and released several times to remove air. The bomb was then charged with hydrogen to a maximum pressure of $150 \mathrm{p} . \mathrm{s} .1$. several times and the pressure drops rocorded. The final total pressure drop was 478 p.s.i. The theoretical pressure drop required was 473 p.s.i. The bomb was fastened on a shaker and shaken during the course of the reaction. When the temperature of the bomb rose noticeably, it was cooled to room temperature in an ice bath. At the end of the reaction, the material was poured out of the bomb and the charcoal filtered off. The tetrahydrofuran and the water produced were taken off under vacuum. The residue was heated with 2,2,4-trimethylpentane and the solvent cooled. After several extractions, a yield of $20.6 \mathrm{~g}$. (64 per cent yield) was obtained. After recrystallization from ligroine (b.p. $66-75^{\circ} \mathrm{C}$ ), the product melted from $56-58^{\circ} \mathrm{C}$. Trials using Faulkner and Woodcock's (1965) procedure for this compound were unsuccessful. They reported that their preparation melted from $57-58^{\circ} \mathrm{C}$.

3-Hydroxy-2,4-dichlorophenoxyacetic acid. - Attempts to diazotize ethyl 3-amino-2,4-dichlorophenoxyacetate and obtain 3-hydroxy-2,4dichlorophenoxyacetic acid have been unsuccessful in this laboratory, although Faulkner and Woodcock (1965) have prepared this compound. 
2,3-Dichlorohydroquinone. - Thís compound was prepared using the procedure described by Conant and Fieser (1923). The product melted at $143^{\circ} \mathrm{C}$ which agreed with the author's work. Attempts to prepare this compound by the rearrangement of 2,5-dichlorobenzoquinone and subsequent saponification as described by Dimroth et al. (1926) failed to yield a usable product.

Ethyl 4-hydroxy-2,3-dichlorophenoxyacetate. - 2,3-Dichlorohydroquinone $(10 \mathrm{~g}$.$) was dissolved in 100 \mathrm{ml}$. of absolute ethanol containing sodium $(1.28 \mathrm{~g}$.$) and refluxed for 2$ hours during the dropwise addition of ethyl bromoacetate $(9.3 \mathrm{~g}$.$) . The excess ethanol was then$ removed under vacuum and the solution diluted with water. The product, which precipitated out of the solution, was filtered off. The yield was $12.7 \mathrm{~g} \cdot(86.5$ per cent yield) and after recrystallization from ligroine (b.p. $60-90^{\circ} \mathrm{C}$ ) melted at $79^{\circ} \mathrm{C}$.

4-Hydroxy-2,3-dichlorophenoxyacetic acid (4-OH-2,3-D). - Attempts to hydrolyze the above ester with acid or base have failed to yield a significant amount of product with sufficient purity for use. Condensation of 2,3-dichlorohydroquinone with bromoacetic acid has also failed to give the desired product. A small sample, however, was supplied by Thomas et al. (1963) and melted at $167-168^{\circ} \mathrm{C}$.

Ethyl 4-hydroxy-2,5-dichlorophenoxyacetate. - This compound was prepared in the same manner as the corresponding 2,3-dichloro-analog s.tarting with 2,5-dichlorohydroquinone. The product melted at $95^{\circ} \mathrm{C}$. 4-Hydroxy-2,5-dichlorophenoxyacetic acid (4-OH-2,5-D). - Ethyl 4-hydroxy-2,5-dichlorophenoxyacetate $(4 \mathrm{~g}$.) was added to $50 \mathrm{ml}$. of 10 per cent aqueous sodium hydroxide and refluxed for 2 hours. The 
solution was then acidified and cooled. White crystals precipitated from the solution. After two recrystallizations from water, $0.6 \mathrm{~g}$. (16.6 per cent yield) of product melting at $166-167^{\circ} \mathrm{C}$ was obtained. The infrared spectrum of this material was identical with that of a sample supplied by Thomas et al. (1963). Their preparation melted at $161-162^{\circ} \mathrm{C}$. Attempts to prepare this compound by condensation of 2,5-dichlorohydroquinone with bromoacetic acid failed, as mentioned previously in the case of the 2,3-dichloro-analog. 


\section{EXPERTMENTAL RESULTS}

Portions of the treated solutions were injected into the gas chromatograph as described in table 1. Ten $\mu$. injections were used for the root extracts and $1 \mu \mathrm{l}$. for the standards. The retention times of the standards are given in table 2. 2,4-D was detectable when as much as $0.1 \mu \mathrm{g}$. was present in the sample injected into the gas chromatograph. A sample containing $0.25 \mu \mathrm{g}$. of the hydroxy-derivatives was necessary for reasonable detection on the equipment used in this study. Since each alkylated extract represented $66 \mathrm{mg}$. of $2,4-D$ substrate and recovery was estimated at 75 per cent or better, the detection threshold of $0.25 \mu \mathrm{g}$. hydroxydichlorophenoxyacetic acid represented excellent sensitivity. In the samples treated with diazomethane, a peak corresponding to 2,4-D was present in all of the 2,4-D treated samples. This peak was masked by the solvent peak due to the higher sensitivity and large sample injection used when diazo-n-propane was the reactant. All other peaks in the 2,4-D treated samples did not correspond to any of the standards and were also present in the control extracts. To determine the disappearance of 2,4-D from the incubation media, three $1 \mathrm{ml}$. samples were taken from one of the flasks at 3 hour intervals during the incubation. These solutions were concentrated under nitrogen almost to dryness and adjusted to $1 \mathrm{ml}$. with methanol. They were then treated with an ethereal solution of 
TABLE 1

\section{Operating Conditions for Gas Chromatography}

Manufacturer

Model

Detector

Column

diameter

length

Carrier

flow

Temperatures

flash heater

column

detector

Electrometer settings

knowns

diazomethane treatment

diazo-n-propane treatment
$F$ and $M$

400

Hydrogen flame ionization

15 per cent SE-30 on Chromosorb W $(60 / 80$ mesh $)$

3/16 inch

6 feet

Helium

$60 \mathrm{ml} . / \mathrm{min}$.
Range

10

10

10
Attenuation

4

8

1 
TABLE 2

Retention Times of Standard Solutions in Methanol

\begin{tabular}{lccc}
\hline $\begin{array}{l}\text { Parent } \\
\text { compound }\end{array}$ & $\begin{array}{l}\text { Methyl ester } \\
\text { methyl ether }\end{array}$ & $\begin{array}{c}\text { Methyl ester } \\
\text { propyl ether }\end{array}$ & $\begin{array}{c}\text { Propyl ester } \\
\text { propyl ether }\end{array}$ \\
\hline min. & min. & min. \\
2,4-D & 4.0 & & 6.5 \\
6-OH-2,4-D & 6.7 & 9.4 & 16.4 \\
5-OH-2,4-D & 8.1 & 10.9 & 19.8 \\
4-OH-2,3-D & 10.2 & 13.5 & 16.0 \\
$4-0 H-2,5-D$ & 8.0 & 11.4 & 21.5 \\
& & & \\
\hline
\end{tabular}


diazo-n-propane, reduced under a stream of nitrogen and readjusted to $1 \mathrm{ml}$. with methanol. These solutions were run on the gas chromatograph. The size of the peaks representing 2,4-D were not reproducible between replicates but there was a continuous decrease in the average peak size as the length of the incubation time increased. There was no peak representing 2,4-D after 12 hours of incubation. This showed that $2,4-D$ was being removed from the solution.

Samples ( $2.5 \mathrm{mg} \cdot)$ of the synthesized hydroxylated derivatives were added to a blank extract and carried through the purification procedure. It is estimated from the relative size of the resulting peaks on the gas chromatograph that more than 75 per cent of each known was recovered in the final solutions. It was observed that the retention times of the knowns added to the blank did not agree with the standards when treated with diazo-n-propane. Since the methanolic extracts had been agitated for several hours, it was suspected that the acids had been converted to methyl esters. In order to resolve this discrepancy, methanolic solutions of the standards in tightly capped tubes were heated in a water bath at $75^{\circ} \mathrm{C}$ for 2 hours. The object of this procedure was to determine whether the phenolic acids could be esterified under very mild conditions. At the end of this time, they were treated with diazon-propane and analyzed on the gas chromatograph. Partial methyl esterification was indicated by the appearance of a second peak other than the propyl ether ester from each of the standards, as shown in table 3. The retention times of the second peaks agreed 
TABLE 3

Relative Peak Heights of Methyl and Propyl Esters of the Propyl Ethers ${ }^{1}$

$\begin{array}{lcc}\text { 6-OH-2,4-D } & 11.0 & 14.5 \\ 5-\mathrm{OH}-2,4-\mathrm{D} & 6.6 & 22.1 \\ 4-\mathrm{OH}-2,3-\mathrm{D} & 3.3 & 23.0 \\ 4-\mathrm{OH}-2,5-\mathrm{D} & 2.8 & 1.9 .6\end{array}$

1 Anhydrous methanolic solutions of the samples, in closed tubes, were heated in a water bath at $75^{\circ} \mathrm{C}$ for 2 hours and then alkylated with the appropriate ethereal diazoalkane. 
with those subjected to the purification procedure and the diazon-propane treatment. The diazomethane treatment gave retention times which agreed with the standards.

4-Hydroxy-2,3-, 4-hydroxy-2,5-, 6-hydroxy-2,4- and 5-hydroxy2,4-dichlorophenoxyacetic acids produced no epinasty on the test plants. 5-Nitro- and 5-amino-4-chloro-2-methylphenoxyacetates showed positive epinasty on the test plants on the day following treatment. Ethyl 6-nitro-4-chloro-2-methylphenoxyacetate produced no epinasty during twelve days following treatment. Ethyl 3-amino2,4-dichlorophenoxyacetic acid showed positive epinasty within 2 hours of treatment, as did 2,4-D. 


\section{DISCUSSION}

The greatest difficulty in this work was the lack of reference compounds for use as standards. The next problem was the determination of an analytical procedure for detection of minute amounts of these substances from biological materials. Preparations for some of the compounds involved in this study were published by others during the course of this work.

Using the procedure of Faulkner and Woodcock (1965), the yield of 3-amino-2,4-dichlorophenoxyacetic acid was very low. In an attempt to obtain a better yield, we used hydrogen in a bomb with palladium on charcoal as a catalyst and obtained a yield of 64 por cent. Faulkner and Woodcock reported a yield of 56 per cent but in this laboratory this yield was never approached using their procedure.

Difficulty was also experlenced in the procedures of diazotization of aromatic amines to phenols reported by the above workers. In attempts to follow their procedures of diazotizing ethyl 3amino-2,4-dichIorophenoxyacetate and ethyl 5-amino-4-chloro-2methylphenoxyacetate to the corresponding hydroxy-acids, none of the desired products were obtained.

6-Hydroxy-4-chloro-2-methylphenoxyacetic acid has nover been synthesized but Gaunt and Evans (1961), using a soil bacterium, isolated a hydroxy-4-chloro-2-methylphenoxyacetic acid believed to be 
the 6-hydroxy-analog. They also isolated a gamma-lactone which presumably would be produced via the former compound. For this reason, an unambiguous synthesis of this compound is of considerable interest. We prepared 6-nitro-4-chloro-2-methylphenoxyacetamide as It is possible that amide substitution would prevent the expected cyclization to a lactam during the reduction of the corresponding nitro compound to the amino analog. This amide may prove to be a useful intermediate in the unambiguous synthesis of 6-hydroxy-4chloro-2-methylphenoxyacetic acid.

Difficulty was also encountered in the last step of the synthesis of 5-chloro-3-methylcatechol as described by Zincke (1918). Due to the dubious structures reported for the intermediates and the low-yielding last step, the preparation of this compound was abandoned. This compound would probably be an intermediate between 6-hydroxy-4-chloro-2-methylphenoxyacetic acid and the previously mentioned gamma-lactone. Because of these difficulties any future attempts to prepare 5-chloro-3-mothyl-catechol should await an unambiguous synthesis of 6-hydroxy-4-chloro-2-methylphenoxyacetic acid such as by the above suggested method. Cleavage of 6-hydroxy4-chloro-2-methylphenoxyacetic acid prepared in this manner with hydriodic acid or a similar reagent would be expected to give in turn 5-chloro-3-methylcatechol unambiguously.

Under the conditions of this work, 2, 4-D was not metabolized to 4-hydroxy-2,3-, 4-hydroxy-2,5-, 6-hydroxy-2,4- or 5-hydroxy-2,4dichlorophenoxyacetic acid in detectable amounts. Conversion at any one time of 0.4 per cent of the original 2,4-D in the incubation 
mixtures to any of the possible hydroxylated intermediates would have been readily detectable. If any of these derivatives were formed, they must have been further metabolized as rapidly as they were produced. It is possible, however, that under some other conditions these derivatives might be detected.

Preparation of more volatile derivatives is necessary for analysis of phenolic acids by gas chromatography. The use of solutions of diazoalkanes in ether to alkylate the carboxyl and hydroxyl groups of the possible metabolites proceeded smoothly during this work. This method has the advantage that one reactant will quickly convert both carboxylic and phenolic hydroxyls to more volatile groups at room temperature. After the initial reaction with the diazoalkane had subsided, a small amount of boron trifluoride was added to further catalyze the reaction and destroy the excess diazoalkane as the methyl ether.

By treating methanolic solutions of standards of the above monohydroxydichlorophenoxyacetic acids with diazomethane and diazo-npropane, it is possible to prepare derivatives which allow separation by means of gas chromatography. Use of only one of the reagents will not produce separable derivatives of all four of the hydroxy-acids under the conditions of this work. Treatment with diazomethane did not separate derivatives of 5-hydroxy-2-4- and 4-hydroxy-2,5-dichlorophenoxyacetic acids. Diazo-n-propane treatment did not separate derivatives of 6-hydroxy-2,4- and 4-hydroxy-2,3-dichlorophenoxyacetic acids. 
Attempted preparations of gamma-lactones mentioned as metabolites of 2,4-D and MCPA by Fernley and Evans (1959) and Gaunt and Evans (1961), respectively, were unsuccessful. Synthesis of these lactones was attempted by oxidation of the corresponding catechol or phenols with monoperphthalic acid as described by Testa (1952). The only compound which could be extracted and identified from these solutions was phthalic acid.

Hydrolysis of ethyl 2,3-dichlorophenoxyacetate to the corresponding acid also failed to yield a usable product. Hydrolysis by both acid and base was attempted but the desired hydroxy-acid was not produced. A high melting compound was extracted which may have been a polymer. Rearrangement of 2,5-dichlorobenzoquinone to the 2,3-dichloro-analog desired as a possible precursor in the synthesis of the previously mentioned compound by the method of Dimroth et al. (1926) also proved unsuccessful. We suspect Dimroth et 르. separated the isomers in a mixture rather than actually causing a rearrangement of the molecule.

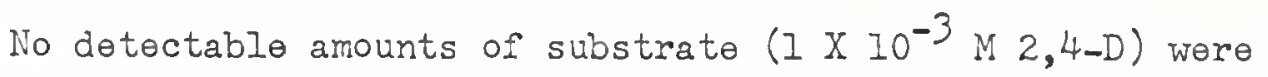
present after 12 hours incubation of excised roots of the plant species studied. The root extracts, however, did give a peak representing 2,4-D which showed that the roots had taken up the herbicide. This indicated that the incubation had not been long enough for all of the 2,4-D to have been converted to some product further removed metabolically from the herbicide than those for which analysis was being made. 
One method which might make identification easier would be the use of methanol as the extraction solvent with addition of boron trifluoride, and subsequent heating to cause esterification of the carboxylic groups. The resulting esters could be treated with various diazoalkanes which would etherify the phenolic groups. This method would enhance dissimilarities in the molecules and might possibly give better separation in gas chromatography.

Otherwise, it would seem advisable to use some extraction solvent other than methanol which would not react with the acids being analyzed. This would eliminate some of the identification problems encountered in this work. Ethyl acetate would be a good solvent to consider.

Another modification in the procedure which might improve the technique would be the use of an electron capture detector on the gas chromatograph. This would probably eliminate most of the peaks noted except those of the compounds containing chlorine. Elimination of peaks for most of the natural products would increase the worker's ablity to identify the compounds being analyzed. Another advantage would be the higher sensitivity to be expected with an electron capture detector.

In the tomato epinasty tests, it is possible that the 5-nitroand 5-amino-4-chloro-2-methylphenoxyacetic acids were contaminated with MCPA since they were prepared from the parent herbicide. However, the purification procedures should reduce this possibility to a minimum. This is particularly true for the amino compound, as its preparation from MCPA requires two steps with associated 
purifications. There should have been no 2,4-D contamination in the othyl 3-amino-2,4-díchlorophenoxyacetate as it was prepared from m-nitrophenol and had no common precursor with 2,4-D. Epinasty was not observed for 6-hydroxy-2,4-, 5-hydroxy-2,4-, 4-hydroxy-2,3- and 4-hydroxy-2,5-dichlorophenoxyacetic acids. 6-Hydroxy-2,4-dichlorophenoxyacetic acid previously had been shown to be inactive by Cavill and Ford (1954). This might be expected as hydroxylation is known to be a prime method of detoxication by biological systems. 
SUMMARY

The object of this work was to determine whether hydroxylated metabolites or further derived compounds were formed during the degradation of 2,4-dichlorophenoxyacetic acid by excised roots of several species of higher plants. Excised roots were incubated in a solution of 2,4-D for periods of 10 and 12 hours at two different hydrogen ion concentrations. The roots were then extracted with methanol. After prepurification by thin layer chromatography, the solutions were treated with diazomethane and diazo-n-propane to alkylate phenolic acids and analyzed by gas chromatography. Synthetic 6-hydroxy-2,4-, 5-hydroxy-2,4-, 4-hydroxy-2,3- and 4-hydroxy2,5-dichlorophenoxyacetic acids were alkylated similarly and used as standarcis in the analysis.

The extracts from the roots contained no detectable amounts of the possible metabolites for which the analysis was being made. All of the extracts from 2,4-D treatments did show a peak with a retention time identical with 2,4-D.

Tomato epinasty tests showed that none of the previously mentioned hydroxylated analogs tested were active. Ethyl 6-nitro-4chloro-2-methylphenoxyacetate also showed no activity in the test. Ethyl 3-amino-2,4-dichlorophenoxyacetate and 2,4-D were very active and began showing epinasty effects within 2 hours of treatment. 5Nitro- and 5-amino-4-chloro-2-methylphenoxyacetic acids also gave 
positive results in the test. The former compound was almost as active as 2,4-D. The latter was less active and the effects didn't appear until the second day after treatment. 


\section{IITERATURE CITED}

Audus, L. J. 1950. Biological detoxication of 2,4-dichlorophenoxyacetic acid in soils. Isolation of an effective organism. Nature 166:356.

Audus, I.J. 1952. The decomposition of 2,4-dichlorophenoxyacetic acid and 2-methyl-4-chlorophenoxyacetic acid in the soil. J. Sci. Food Agr. 3:268.

Bach, M. K. 1961. Netabolites of 2,4-dichlorophenoxyacetic acid Irom bean stems. Plant Physiol. 36:558.

Bell, G. R. 1960. Studies on a soil Achromobacter which degrades 2,4-dichlorophenoxyacetic acid. Can. J. Microbiol. 6:325.

Bocks, S. M., J.R. I. Smith, and R. O. C. Norman. 1964. Hydroxylation of phenoxyacetic acid and anisole by Aspergillus niger (van Tiegh). Nature 201:398.

Burger, K., I. C. MacRae, and M. Alexander. 1962. Decomposition of phenoxyalkylcarboxylic acids. Soil Sci. Soc. Am. Proc. 26:243.

Byrde, R. J.W., J.F. Harris, and D. Woodcock. 1956. Fungal detoxication. The metabolism of $\omega$-(2-naphthyloxy)-n-alkylcarboxylic acids by Aspergillus niger. Biochem. J. $64: 1 \overline{5} 4$.

Byrde, R. J.W., and D. Woodcock. 1957. Fungal detoxication. 2. The metabolism of some phenoxy-n-alkylcarboxylic acids by Aspergillus niger. Biochem. J. 65:682.

Byrde, R. J. W., and D. Woodcock. 1958. Fungal detoxication. 3. The metabolism of $\omega$-(2-naphthyloxy)-n-alkylcarboxylic acids by Sclerotinia laxa. Biochem. J. 69:19.

Canny, M. J., ana K. Markus. 1960. The breakdown of 2,4-dichlorophenoxyacetic acid in shoots and roots. Australian J. Biol. Sci. 4:486.

Cavill, G. W. K., and D. L. Ford. 1954. The chemistry of plantgrowth regulators. Part I. 2:4-Dichloro-6-hydroxyphenoxyacetic acid and related compounds. J. Chem. Soc.:565.

Clifford, D. R., and D. Woodcock. 1964. Metabolism of phenoxyacetic acid by Aspergillus niger van Tiegh. Nature 203:763. 
Conant, J. B., and I. F. Fieser. 1923. Reduction potentials of quinone. I. The effect of the solvent on the potentials of certain benzoquinones. J. Am. Chem. Soc. 45:2194.

Dagley, S., W. C. Evans, and D. W. Ribbons. 1960. New pathways in the oxidative metabolism of aromatic compounds by microorganisms. Nature 188:560.

Dickens, F., and H. E. H. Jones. 1961. Carcinogenic activity of a series of reactive lactones and related substances. Brit. J. Cancer $15: 85$.

Dickens, F., and H. E.H. Jones. 1963. Further studies on the carcinogenic and growth-inhibitory activity of lactones and related substances. Brit. J. Cancer 17:100.

Dimroth, O., H. Eber, and K. Wehr. 1926. III. Uber das benzochinondichlorid. Ann. 446:132.

Eckstein, Z., E. Dyszer, and T. Niedzwialowska. 1964. O nitrowaniu estrow kwasow 2-metylo- oraz 2-etylo-4-chlorofenoksy-octowego. I. Poszukiwanie metody syntezy analogow alkilowych $2,4,5-\mathrm{T}$. Roczniki Chemii 38:5I.

Evans, W. C., and B.S.W. Smith. 1951. The oxidation of aromatic compounds by soil bacteria. Biochem. J. 49:x.

Evans, W. C., B. S. W. Smith, R. P. Iinstead, and J. A. Elvidge. 1951. Chemistry of the oxidative metabolism of certain aromatic compounds by micro-organisms. Nature 168:772.

Evans, W. C., and B.S. W. Smith. 1954. The photochemical inactivation and microbial metabolism of the chlorophenoxyacetic acid herbicides. Biochem. J. 57:xxx.

Evans, W. C. 1956. Biochemistry of the oxidative metabolism of aromatic compounds by micro-organisms. Ann. Rept. Progr. Chem. (Chem. Soc. London) 53:279.

Evans, W. C., and P. Moss. 1957. The metabolism of the herbicide, p-chlorophenoxyacetic acid by a soil micro-organism--the formation of a s-chloromuconic acid on ring fission. Biochem. J. $65: 8$.

Faulkner, J.K., and D. Woodcock. 196la. Metabolism of chlorophenoxyacetic acids by Aspergillus niger. Chem. Ind. (Iondon): i366.

Faulkner, J.K., and D. Woodcock. 1961b. Fungal detoxication. Part V. Metaboiism of ㅇ- and p-chlorophenoxyacetic acids by Aspergillus niger. J. Chem. Sö. :5397. 
Faulkner, J.K., and D. Woodcock. 1964. Metabolism of 2,4-dichlorophenoxyacetic acid ("2,4-D") by Aspergillus niger van Tiegh. Nature 203:865.

Faulkner, J.K., and D. Woodcock. 1965. Fungal detoxication. Part VII. Metabolism of 2,4-dichlorophenoxyacetic and 4-chloro-2methylphenoxyacetic acids by Aspergillus niger. J. Chem. Soc.: 1187.

Fawcett, C. H., J. M. A. Ingram, and R. L. Wain. 1954. The $\beta-$ oxidation of phenoxyalkylcarboxylic acids in the flax plant in relation to their growth-regulating activity. Proc. Roy. Soc. (London), Ser. B 142:60.

Fawcett, C. H., R. M. Pascal, M. B. Pybus, H. F. Taylor, R. I. Wain, and F. Wightman. 1959. Plant growth-regulating activity in homologous series of $w$-phenoxyalkanecarboxylic acids and the influence of ring substitution on their breakdown by $\beta$-oxidation within plant tissues. Proc. Roy. Soc. (London), Ser. B 150:95.

Fernley, H. N., and W. C. Evans. 1959. Metabolism of 2,4-dichlorophenoxyacetic acid by soil Pseudomonas: Isolation of a-chloromuconic acid as an intermediate. Biochem. J. 73:22P.

Gaunt, J.K., and W. C. Evans. 1961. Metabolism of 4-chloro-2methylphenoxyacetic acid by a soil micro-organism. Biochem. J. $79: 25 \mathrm{P}$.

Groves, I. G., E. E. Turner, and G. I. Sharp. 1929. IXXVI. - The scission of diaryl ethers and related compounds by means of piperidine. Part II. The nitration of 2:4:4'-trichlorodiphenyl ether, and of 2:4-dichlorophenyl p-toluenesulphonate and benzoate. J. Chem. Soc.:512.

Holley, R. W. 1952. Studies on the fate of radioactive 2,4-dichlorophenoxyacetic acid in bean plants. II. A water soluble transformation product of 2,4-D. Arch. Biochem. Biophys. 35:171.

Leafe, E. I. 1962. Metabolism and selectivity of plant-growth regulator herbicides. Nature 193:485.

Moszew, J., and J. Wojciechowski. 1945. Studia nad synteza regulatorow wrostu roslin, pochodnych fenoli duruvodorotlenowych. Roczniki Chemii $28: 445$.

Newman, A. S., and J.R. Thomas . 1949. Decomposition of 2,4dichlorophenoxyacetic acid in soil and liquid media. Soil Sci. Soc. Am. Proc. 14:160.

Payne, G. B. 1962. Monoperphthalic acid. Org. Syn. 42:77. 
Ribbons, D. W., and W. C. Evans. 1962. Oxidative metabolism of protocatechuic acid by certain soil Pseudomonads: A new. ringfission mechanism. Biochem. J. 83:482.

Rogoff, M. H., and J.J. Reid. 1956. Bacterial decomposition of 2,4-dichlorophenoxyacetic acid. J. Bacteriol. 71:303.

Rogoff, M. H. 1961. Oxidation of aromatic compounds by bacteria. Advan. Appl. Microbiol. 3:193.

Steenson, T. I., and N. Walker. 1956. Observations on the bacterial oxidation of chlorophenoxyacetic acids. Plant Soil 8:17.

Steenson, T. I., and N. Walker. 1957. The pathway of breakdown of 2,4-dichloro- and 4-chloro-2-methylphenoxyacetic acid by bacteria. J. Gen. Microbiol. 16:146.

Testa, E. 1952. Oxydationen durch Wasserstoffsuperoxyd und Persauren die zun spaltung von C-C bindungen fuhren. JurisVerlag, Zurich. $49 \mathrm{p}$.

Thomas, E. W., B. C. Loughman, and R. G. Powell. 1963. Hydroxylation of phenoxyacetic acid by stem tissue of Avena sativa. Nature 199:73.

Thomas, E. W., B. C. Loughman, and R. G. Powell. 1964a. Metabolic fate of some chlorinated phenoxyacetic acids in the stem tissue of Avena sativa. Nature 204:286.

Thomas, E. W., B. C. Loughman, and R. G. Powell. 1964b. Metabolic fate of 2,4-dichlorophenoxyacetic acid in the stem tissue of Phaseolus vulgaris. Nature 204:884.

Wain, R. I., and F. Wightman. 1954. The growth-regulating activity of certain $\omega$-substituted alkylcarboxylic acids in relation to their B-oxidation within the plant. Proc. Roy. Soc. (Iondon), Ser. B $142: 525$.

Webley, D. M., R. B. Duff, and V.C. Farmer. 1955. Beta-oxidation of fatty acids by Nocardia opaca. J. Gen. Microbiol. 13:361.

Webley, D. M., R. B. Duff, and V. C. Farmer. 1958. The influence of chemical structure on $\beta$-oxidation by soil Nocardias. J. Gen. Mícrobiol. $18: 733$.

Wilcox, M., D. E. Moreland, and G. C. Klingman. 1963. Aryl hydroxylation of phenoxyaliphatic acids by excised roots. Physiol. Plantarum Ió:565. 
Williams, R. T. 1950. Biological oxidation of aromatic rings. Biochem. Soc. Symp. (Cambridge, Engl.) No. 5. $96 \mathrm{p}$.

Williams, R. T. 1959. Detoxication mechanisms. The metabolism and detoxication of drugs, toxic substances and other organic compounds. Chapman and Hall, Iondon. $795 \mathrm{p}$.

Zincke, T. 1918. Uber die einwirkung von salpetersaure auf halogenderívate von o-alkylphenolen. Ann. 417:191. 


\section{BIOGRAPHY}

Norman Glaze was born in Washington, D. C., on January 16 , 1934. He attended public schools in Hyattsville, Maryland, and was graduated from Northwestern High School in 1952. He obtained the Bachelor of Science degree from the University of Maryland in 1957. Upon completion, he was inducted into the U. S. Army and served for two years. After completion, he reentered the University

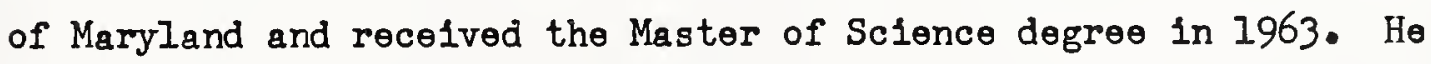
then transferred to the University of Florida for work on the Doctor of Phllosophy degree. 
This dissertation was prepared under the direction of the chairman of the candidate's supervisory committee and has bee. approved by all members of that comittee. It was submitted to the Dean of the College of Agriculture and to the Graduate Council, and was approved as partial fulfillment of the requirements for the degree of Doctor of Philosophy.

April, 1966

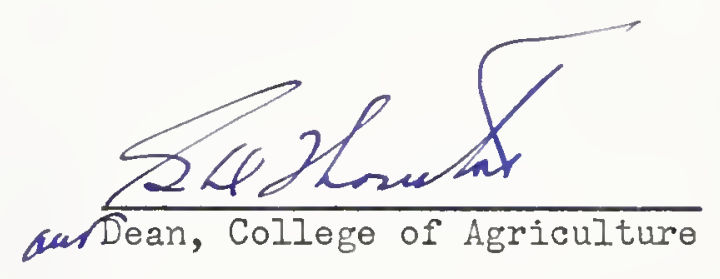

Dean, Graduate School

Supervisory Committeo:
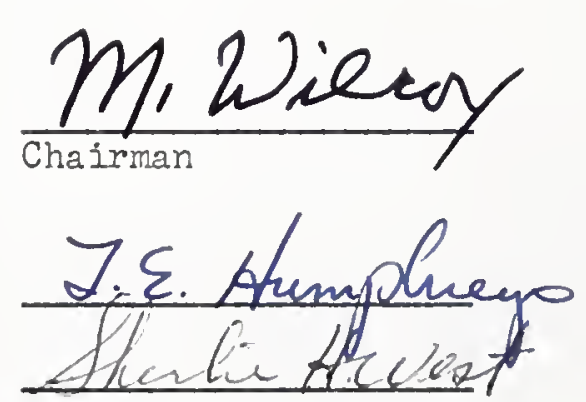

3180 